\title{
Phonological priming in the lexical decision task: A failure to replicate
}

\author{
RANDI C. MARTIN and CARY ROBB JENSEN \\ Rice University, Houston, Texas
}

\begin{abstract}
Some models of the lexicon predict that recognition of words should produce activation spreading to phonologically related words. Consistent with this prediction, Hillinger (1980) demonstrated priming in a visual lexical decision task for word targets preceded by graphemically similar or graphemically dissimilar primes that rhymed with the target. In Experiment 1, we investigated whether this phonological priming effect occurred automatically or because of subject strategies. Although semantically associated primes produced significant facilitation in Experiment 1, no evidence of phonological priming was obtained. Experiments 2 to 5 were conducted in an attempt to obtain the phonological priming effect. Experiment 5 was a replication of one of Hillinger's experiments. In none of these experiments was phonological priming observed. These results indicate either that the lexicon is not organized such that spreading activation occurs on the basis of phonological similarity, or that visual lexical decisions are made without phonological mediation.
\end{abstract}

In contrast to the numerous studies of semantic priming, relatively few studies have been carried out on phonological priming. However, some models of the lexicon clearly predict that priming on the basis of phonological similarity should occur. In Collins and Loftus' (1975) theory of semantic processing, a lexical network containing the names of concepts was assumed to exist separately from a semantic network that contained the concepts themselves. Collins and Loftus proposed that the lexical network is organized on the basis of phonological similarity. They assumed that activation spreads in the lexical network from one name to phonologically related names, in a manner similar to the spread of activation in the semantic network from one concept to semantically related concepts. Forster's (1976) model of the mental lexicon also includes a separate structure containing the phonological representation of words; this structure is assumed to be organized on the basis of phonological similarity. According to Forster's model, the lexicon consists of a master file and several access files. The master file contains all of the information usually attributed to lexical entries-that is, information about the semantic, syntactic, graphemic, and phonological characteristics of each word. In word recognition, two of the access files-the visual and the phonological-are used to gain access to the master file. Although Forster (1976) did not address the possibility of activation spreading in the phonological access file, Hillinger (1980) elaborated on this model,

This research was supported in part by NIH Grant 19652 to Rice University. The authors would like to thank an anonymous reviewer for extensive comments on an earlier version of this paper, which led to many improvements in the manuscript. Requests for reprints should be mailed to Randi C. Martin, Psychology Department, Rice University, P.O. Box 1892, Houston, Texas 77251 . proposing that once an entry in the phonological access file was located, activation spread automatically to neighboring entries.

In a widely cited study in which they measured times taken to decide whether simultaneously presented pairs of letter strings were words, Meyer, Schvaneveldt and Ruddy (1974) demonstrated facilitation for graphemically similar rhyming word pairs (e.g., late-mate) and inhibition for graphemically similar nonrhyming word pairs (e.g., lemon-demon) relative to unrelated word pairs; however, these effects were not attributed to activation spreading between lexical entries. Meyer et al. argued that subjects were encoding the first word of the pair by using a grapheme-to-phoneme conversion process, and that they were biased toward using the same set of conversion rules for the second word if it was graphemically similar to the first. In the case of the graphemically similar rhyming words, the bias would result in faster phonological recoding for the second word and faster reaction times (RTs). In the case of the graphemically similar nonrhyming words, the application of these rules to the second word would generally not result in a real word, and the subject would have to make a second attempt at phonologically coding the word, resulting in longer RTs.

Hillinger (1980) presented evidence against the encoding-bias interpretation of these results. He argued that if the tendency for subjects to respond more rapidly to graphemically similar rhyme pairs derived from encoding bias, the effect should not be present if the first word were presented auditorily. Second, there should be no facilitation for visually presented rhyme pairs that were graphemically dissimilar (e.g., eight-mate). In one experiment, Hillinger obtained faster RTs for target words preceded by an auditorily presented rhyme. In two other experiments, using visually presented primes and targets, 
he found significant facilitation for words preceded by graphemically dissimilar rhymes as well as for words preceded by graphemically similar rhymes.

Hillinger (1980) argued that the priming effect for rhyming words derived from activation spreading in the phonological access file. In order for this process to occur for visually presented words, it would have to be the case that the phonological representation of the priming word was accessed during word recognition, and that the activation spreading to related phonological entries speeded the recognition of the target word. Hillinger suggested that the phonological access file would be used to access the master file even in visual word recognition, if the lexical decision task was designed to encourage the use of a phonemic recoding process. After the entry for the phonological representation of the priming word was located in the phonological access file, activation would spread to neighboring entries, and, as it did so, would make these entries more sensitive to further input. On the basis of the results of a study by Shulman, Hornak, and Sanders (1978), Hillinger suggested that the inclusion of phonologically regular nonwords could suffice to induce subjects to use a phonological recoding strategy. Hillinger also implied that if subjects were not induced to use a phonological recoding strategy, access would occur through a visual access file; then, one might expect to see priming on the basis of visual similarity.

Thus, Hillinger's (1980) account of the rhyme priming effect depends crucially on the assumption that subjects use phonological recoding during visual word recognition. However, there is inconclusive evidence concerning whether phonological recoding takes place during a lexical decision task, even when pronounceable nonwords are used. For example, inconsistent results have been obtained with regard to whether irregular spellingsound correspondences (as, e.g., for the word sew) affect lexical decision times. Although some studies have reported longer RTs for irregular than for regular words (Bauer \& Stanovich, 1980; Parkin \& Underwood, 1983), recent evidence from Seidenberg, Waters, Barnes, and Tanenhaus (1984) indicates that these effects may have been due to orthographic irregularity. When these researchers controlled for orthographic regularity, they found no effect for irregular spelling-sound correspondences in a lexical decision task. Also, although longer times have been found to be needed by subjects to make nonword decisions with regard to pseudohomophones (i.e., nonwords such as brane that would be pronounced like words) as opposed to other nonwords (Coltheart, Davelaar, Jonasson, \& Besner, 1977; Patterson \& Marcel, 1977), there is evidence that these longer times may have resulted because pseudohomophones tend to have greater visual similarity to real words than other nonwords do (Martin, 1982; but see Besner \& Davelaar, 1983). These results, as well as many others, have led several researchers to propose that although phonological recoding or phonological activation may occur in parallel with visual access to the lexicon, visual access occurs more quickly. Thus, lexical decisions are usually based on visual access (Coltheart, 1978; Seidenberg et al., 1984). In order for rhyme priming to occur in a lexical decision task, the phonological activation afforded by processing the prime would have to speed up the phonological processing of the target word sufficiently for access on a phonological basis to be faster than visual access.

Although the hypothesis of spreading activation might account for rhyme facilitation effects for graphemically similar and graphemically dissimilar rhymes, it cannot account for the inhibition with regard to graphemically similar nonrhymes. Hillinger (1980) argued that the rhyme priming effect and the inhibitory effect derive from different sources, because different variables affect the facilitatory and inhibitory effects. For example, in the experiments reported by Meyer et al. (1974), the size of the inhibitory effect was greatly decreased by sequential rather than simultaneous presentation of the prime and target, while the size of the facilitatory effect was similar for both sequential and simultaneous presentation. Hillinger suggested that the inhibitory effect may in fact derive from a short-lived encoding bias that depends on an experimental procedure that highlights the word pairs' graphemic similarity.

Hillinger's (1980) finding of priming for graphemically dissimilar rhymes could not be accounted for on the basis of encoding bias or visual similarity between prime and target. Thus, if it reflects an automatic activation of phonologically similar words, the effect has important implications for the structure of the lexicon and the process of visual word recognition. However, because of the design of Hillinger's experiments, it is possible that his rhyme priming effects were due to his subjects' strategies rather than to any automatic processes involved in word recognition. In his experiments, the subjects made a decision with respect to the first word before the second word appeared. The subjects may have noticed that many of the word pairs rhymed, and, upon seeing the first word, they may have generated possible rhymes. Since expected words are responded to more quickly than unexpected words, a facilitation effect would have been observed for the second word. Studies of semantic priming have differentiated two types of priming, one automatic and one due to conscious strategies. According to criteria proposed by Posner and Snyder (1975), an automatic effect should occur at very short delays after presentation of the stimulus. Also, an automatic effect should have only facilitatory effects and not inhibitory effects. Strategic effects, on the other hand, should occur at longer delays and have both facilitatory and inhibitory effects. Neely (1977) showed that semantic priming could be detected at delays as short as $\mathbf{2 5 0}$ msec between the onset of the prime and the onset of the target word. An inhibitory effect for unrelated words did not become evident until about a 400-msec stimulus onset asynchrony (SOA). Neely proposed that very early priming effects could be attributed to an automatic effect, but after about $400 \mathrm{msec}$ both automatic and strategic effects would be in operation. 
Hillinger (1980) argued that the rhyme facilitation he found was not due to subject strategies by pointing to the short time intervals between the presentation of the prime and the target in his experiment. However, in his experiments, the subjects responded to the prime, and then the target appeared. The difference in prime and target onset time thus depended on the time taken to respond to the prime-about $550 \mathrm{msec}$ on the average. Certainly the time parameters reported by Neely (1977) would suggest that Hillinger's subjects may have had time to generate possible rhymes on at least some trials while executing a response to the prime.

Experiment 2 of the Hillinger (1980) study included some trials in which a nonword prime rhymed with its word target. Hillinger argued that if the subjects were generating rhyme targets, facilitation should have appeared on these trials relative to trials with nonwordunrelated-word pairs, but no facilitation was found. However, it is quite possible that his subjects obtained phonological representations for words on a whole-word basis, rather than by grapheme-to-phoneme conversion (Evett \& Humphries, 1981; Humphrey, Evett, \& Taylor, 1982; Taft, 1982). If the subjects were not using grapheme-to-phoneme conversion, phonological representations would not be accessed for nonwords, and no facilitation for nonword primes would be expected even if the subjects were employing a rhyme generation strategy on word-prime trials. Thus, Hillinger's results do not rule out the possibility that the rhyme priming he observed was due to strategic rather than automatic processes.

Because of the importance of priming with graphemically dissimilar rhymes for theories of the lexicon, and because Hillinger's study is the only one to report it, the present experiments were undertaken in an attempt to replicate the finding and to determine whether it could be attributed to automatic spreading activation.

\section{EXPERIMENT 1}

Experiment 1 examines whether rhyme priming from graphemically dissimilar primes is automatic or strategically mediated. This issue was left unresolved by Hillinger's (1980) research, because his subjects responded to both the prime and target and thus had time to use the prime to generate an expectancy for a rhyming target. We avoided this problem here by having the subjects simply read the prime silently rather than respond to it, and by using an SOA that ought to have been short enough to eliminate strategically mediated priming. If rhyme priming from graphemically dissimilar primes is automatic, it should occur at a short SOA, relative to the neutral priming condition, and it should be unaccompanied by inhibition in the unrelated priming condition. On the other hand, if rhyme priming is purely strategic, it should occur only at the long SOA.

\section{Method}

Design and Stimulus Materials. Both SOA (250 msec vs. $550 \mathrm{msec}$ ) and prime-target relationships were within-subject fac- tors. In Experiment 1, a word target was preceded by either a graphemically similar rhyme (FOOL-spool), a graphemically dissimilar rhyme (RULE-spool), a word for which the prime was a primary associate (THREAD-spool), an unrelated word (WALTZspool), or a neutral control prime (XXXXX-spool). Three types of prime-target pairs were employed as nonword trials. These were graphemically similar (and arguably phonemically similar) wordprime-nonword-target pairs (SHEAR-kear), graphemically dissimilar word-prime-nonword-target pairs (YET-kear), and neutralcontrol-prime-nonword-target pairs (XXXXX-kear). The nonwords were created by changing one or two letters of a one-syllable word so that the result was pronounceable and orthographically acceptable.

The design of the experiment necessitated that a target word meet the following criteria: (1) it must be a high associate of a word, (2) it must rhyme with at least one graphemically similar word, and (3) it must rhyme with at least one graphemically dissimilar word. A target word was determined to be a high associate of a prime word if it was one of the highest responses to the prime according to the Keppel and Strand free-association test (Keppel \& Strand, 1970), or if it was generated by more than one respondent in a pilot study in which 32 subjects (different from those participating in the lexical decision experiment) were given 100 words and asked to write down the first two words that came to mind.

Experiment 1 consisted of 160 trials, 80 word-target trials and 80 nonword-target trials. The 80 word targets were divided into five groups of 16 targets each (see Appendix A for a list of the stimuli). Five stimulus files were created by matching each target group with each type of prime in a Latin square design. Within each group of targets, half of the targets were chosen to be presented at the short SOA (250 msec) and the other half at the long SOA $(550 \mathrm{msec})$. The appearance of a particular target at a particular SOA was counterbalanced across subjects.

The 80 nonword targets were also divided into five groups of 16 targets each. In each stimulus set, one group of targets was preceded by a graphemically similar word prime, one group was preceded by a neutral control prime, and three groups were preceded by a graphemically dissimilar word prime. As was done with respect to the word-target trials, the type of prime was rotated through the target groups in a Latin square design. Also as was done with respect to the word-target trials, half of the targets in each group were presented in the 250-msec SOA condition and the other half were presented in the 550-msec SOA condition. The five word-target stimulus sets were randomly paired with the five nonword-target stimulus sets.

The combinations of primes and targets described above resulted in each stimulus set's containing 16 neutral control primes, 16 graphemically similar word primes, and $\mathbf{4 8}$ graphemically unrelated word primes for both the word targets and the nonword targets (16 of the graphemically unrelated word-word trials were semantically related pairs).

In order to control for the graphemic similarity between the graphemically dissimilar rhyming pairs and the unrelated-word pairs, unrelated-word targets were selected such that the unrelated primes shared the same average number of letters with the target as did the graphemically dissimilar thyming primes. Primes were presented in uppercase letters, but targets were presented in lowercase letters. This was done to reduce any visual contribution to an effect in the graphemically similar rhyming condition.

Apparatus. The subjects were tested individually in closed, sound-dampened cubicles. All stimuli were presented on a TRS 80 Model III or Model 4 microcomputer. The subjects initiated trials and indicated responses by pressing keys on the computer's keyboard. Stimulus presentation, data collection, and trial randomization were controlled by the computer program.

All of the experiments used the same apparatus, therefore, this information will not be repeated.

Procedure. The subjects were told that they were to indicate whether a presented letter string was a real English word or a 
meaningless nonword. The subjects were told to initiate each trial by pressing the space bar on the computer keyboard with the left hand. Once a trial was initiated, the computer screen stayed blank for $1 \mathrm{sec}$ before a plus sign appeared at its center. One second later, the plus sign was replaced with either a word or a string of Xs. The subjects were told to read these primes, but they were not required to make any overt responses to them.

The prime was presented on the screen for $200 \mathrm{msec}$. In the 250 msec SOA condition the screen was blank for $50 \mathrm{msec}$ before the target was presented, and in the 550-msec condition the screen was blank for $350 \mathrm{msec}$. Both the prime and target were presented at the same location on the screen as they were by Neely (1976), who used tachistoscopic presentation. The subjects were instructed to respond to the target as quickly and as accurately as possible, pressing the 1 key on the computer's 10-key pad with the forefinger to indicate that the target was a word, or the 2 key on the 10-key pad with the middle finger to indicate that the target was a nonword. Once a subject responded, the computer screen was erased and left blank for $2 \mathrm{sec}$ before the subject was prompted to initiate the next trial.

Prior to Experiment 1, each subject performed 30 practice trials. The subjects were not informed of the possible prime-target relationships. However, the practice trials were constructed so that the relative proportion of each prime-target trial type matched those of the experimental trials.

Subjects. Sixty Rice University undergraduates participated in the experiment in order to fulfill a class requirement. These subjects were assigned to stimulus sets randomly, with the restriction that each group of 12 subjects was presented with one of the five stimulus sets.

\section{Results}

In the analysis of all the experiments reported in this paper, all trials with RTs over $2,000 \mathrm{msec}$ or under $100 \mathrm{msec}$ were counted as errors and omitted from the RT analyses. These trials, in which the RTs were unacceptably fast or slow, accounted for less than $0.5 \%$ of all trials in each experiment. In the analyses of RTs, the mean RTs for each condition were computed, excluding incorrect responses. In the analysis of errors, the percentage of errors for each condition was computed. In the analysis treating subjects as a random effect, measures were computed for each subject for each condition. In the analysis treating items as a random effect, measures were computed for each word and nonword for each condition. In all cases, specific comparisons were made using the error term for that comparison. The means reported in the tables are based on the analyses treating subjects as a random factor. Since the data were treated in this manner in this and all subsequent experiments, the preceding description will not be repeated.

The subjects responded slower in the 250-msec SOA condition than in the 550-msec SOA condition (619 msec vs. $600 \mathrm{msec}):[F(1,59)=10.18, M S \mathrm{Se}=4,956, p=$ .002 by subjects, and $F(1,79)=12.80, M S e=5,579$, $p=.0006$ by items]. The main effect for type of prime was significant in the analysis of RTs both by subjects $[F(4,236)=3.98, M S e=4,229, p=.004]$ and by items $[F(4,316)=3.22, M S e=8,208, p=.012]$. However, the interaction between SOA and type of prime was not significant in either the analysis by subjects or by items (both $p s>.25$ ).

Each prime-target type was compared individually to the neutral control condition, using the appropriate error term (Myers, 1979). Even though the overall analysis revealed no interaction between prime type and SOA, this interaction was examined in each of the individual analyses in order to determine whether there was any suggestion of strategically mediated priming effects that occurred only at the longer SOA. The comparisons of each prime type with the neutral controls revealed that only the semantically related condition resulted in significantly different RTs $[F(1,59)=10.20, M S e=4,719, p=.002$ by subjects, and $F(1,79)=8.06, M S e=9,360, p=.005$ by items]. As shown in Table 1, semantically related items were responded to faster than were the neutral controls, by $29 \mathrm{msec}$. The RTs for responses to targets preceded by phonologically related primes did not differ significantly from the RTs for the neutral control condition, in the analyses by either subjects or items (all $p s>.20$ ). In none of these analyses did the influence of type of prime interact with the SOA manipulation. For the two interactions of most interest-that is, the interaction of SOA with the priming effect for the two types of rhyming primesthe effects did not approach significance: both $F \mathrm{~s}<1.0$ in the analyses by subjects, and both $p s>.25$ in the analyses by words.

Jonides and Mack (1984) have argued that a neutral control condition that uses the same stimulus on all trials, like the control employed here, may underestimate priming effects, because the neutral control prime may require less encoding time than word primes do. That is, with the neutral control stimulus, subjects may have completed the processing of the stimulus before the target appears. On word-prime trials, subjects may still be encoding the prime when the target appears, thus resulting in longer RTs. A comparison of the phonological priming conditions with the unrelated condition rather than the neutral control condition should provide a lenient test for facilitation. The encoding time for the prime in the unrelated condition should be the same as it is for the phonological primes, since the stimuli are words. If any effect is ex-

Table 1

Mean Reaction Times and Percent Errors for Experiment 1 by Subjects

\begin{tabular}{|c|c|c|c|c|c|c|}
\hline \multirow[b]{2}{*}{ Type of prime } & \multicolumn{2}{|c|}{ 250-msec SOA } & \multicolumn{2}{|c|}{ 550-msec SOA } & \multicolumn{2}{|c|}{ Mean } \\
\hline & RTs & Errors & RTs & Errors & RTs & Errors \\
\hline Graphemically similar rhymes & 610 & $4.37 \%$ & 606 & $2.50 \%$ & 608 & $3.44 \%$ \\
\hline Graphemically dissimilar rhymes & 624 & $5.21 \%$ & 594 & $3.33 \%$ & 609 & $4.27 \%$ \\
\hline Semantically related & 597 & $1.67 \%$ & 583 & $1.67 \%$ & 590 & $1.67 \%$ \\
\hline Unrelated & 637 & $4.97 \%$ & 603 & $4.97 \%$ & 620 & $4.97 \%$ \\
\hline Neutral control & 625 & $4.17 \%$ & 613 & $2.71 \%$ & 619 & $3.44 \%$ \\
\hline
\end{tabular}


pected for targets in the unrelated condition relative to a neutral control, one might predict inhibition (Neely, 1977; Posner \& Snyder, 1975). A comparison of the RTs in the graphemically dissimilar rhyme priming condition with the RTs in the unrelated condition showed no significant main effect $[F(1,59)=1.80, M S e=4,007$, $p>.15$ by subjects, and $F(1,79)=.99, M S e=7,527$ by items], and no interaction with SOA $[F(1,59)=.09$, $M S \mathrm{e}=1,855$ by subjects and $F(1,79)=.12, M S \mathrm{e}=838$ by items]. A comparison of RTs in the graphemically similar rhyme priming condition with RTs in the unrelated condition also showed no significant main effect $[F(1,59)$ $=2.01, M S e=4,182, p>.15$ by subjects and $F(1,79)$ $=1.58, M S \mathrm{e}=7,921, p>.20$ by items]. The interaction with SOA was significant in the analysis by subjects $[F(1,59)=4.72, M S e=2,679, p=.03]$, but not in the analysis by items $[F(1,79)=2.59, M S e=6,784, p=$ .11. Thus, even according to this possibly more lenient test, there was no priming for targets that were preceded by phonologically related primes.

Although the RTs in the rhyme priming conditions did not differ significantly from those for the neutral control condition, the mean RTs for these conditions were faster than for the neutral control condition-though not as fast as for the semantically related prime condition. In order to verify that targets preceded by semantically related primes were responded to significantly faster than those preceded by rhyming primes, both rhyme conditions were compared with the semantically related condition. Significantly faster times for the semantic priming condition were found in both comparisons: $F(1,59)=7.42, M S \mathrm{e}=$ $2,552, p=.008$ in the analysis by subjects and $F(1,79)$ $=4.18, M S e=8,552, p=.04$ in the analysis by items, for the comparison with the graphemically similar rhyming condition; and $F(1,59)=5.80, M S e=3,592, p=$ .02 in the analysis by subjects and $F(1,79)=4.89$, $M S \mathrm{e}=8,742, p=.03$ in the analysis by items, for the comparison with the graphemically dissimilar rhyming condition. Furthermore, these differences did not interact significantly with the SOA manipulation (all $p s>.30$ ).

The pattern of effects for prime types observed in the analysis of errors mimicked those observed in the analysis of RTs. There was a significant main effect due to type of prime-target relationship in the analysis by subjects $[F(4,236)=4.27, M S \mathrm{e}=42, p=.002]$ and in the analysis by items $[F(4,316)=3.81, M S e=63, p=$ .04]. As was done in the analysis of RTs, errors for each type of prime-target relationship were compared individu- ally to those observed in the neutral control condition. These analyses revealed that a semantic prime-target relationship resulted in fewer errors than the neutral control condition in both the analysis by subjects $[F(1,39)=5.83$, $M S e=36, p=.02]$ and by items $[F(1,79)=5.33$, $M S e=52, p=.023]$. None of the other relationships resulted in error percentages significantly different from those in the neutral control condition, in either the analyses by subjects or the analyses by items (all ps $>.10$ ).

There was a marginally significant effect due to SOA on error percentages $[F(1,59)=3.84, M S e=42, p=$ .054 by subjects, and $F(1,79)=3.75, M S e=62, p=$ .056 by items]. The subjects responded with a greater number of errors in the 250 -msec SOA than in the 550msec SOA ( $4.04 \%$ vs. $2.96 \%$ ). As in the analysis of RTs, there was no reliable interaction between type of prime-target relationship and SOA in either the analysis by subjects or the analysis by items (both $F \mathrm{~s}<1.0$ ).

The analysis of nonword-target trials was possible in Experiment 1, since all nonword targets appeared in each priming condition. Table 2 shows the mean RTs and error rates for the nonword trials by SOA. In the analysis of RTs there was a significant effect due to the SOA manipulation $[F(1,59)=13.04, M S e=3,722, p=.0006$ by subjects, and $F(1,79)=8.54, M S e=6,665, p=.005$ by items]. As in the analysis of word trials, the subjects responded slower in the 250-msec SOA condition than in the 550-msec SOA condition. This effect was mirrored in the analysis of errors, in that subjects made more errors in the 250-msec SOA condition than in the 550-msec SOA condition $[F(1,59)=10.29, M S e=35, p=.002$ by subjects, and $F(1,79)=6.86, M S e=71, p=.01$ by items].

The only other effect to be significant in these analyses was a main effect of prime type by subjects $[F(2,118)=$ $4.56, M S e=2,193, p=.01]$. However, this effect was not significant in the analysis by items $[F(2,158)=1.55$, $M S e=5,609, p=.21]$.

\section{Discussion}

Experiment 1 was intended to test whether the rhyming facilitation found by Hillinger (1980) could be attributed to subject strategies. If so, it was expected that rhyme priming would be found at only the long SOA. On the other hand, if rhyme facilitation were automatic, it was expected to be found at both SOAs. Unexpectedly, no rhyme facilitation was found at either SOA. Semantic facilitation, however, was observed at both SOAs. The semantic effect confirms that the subjects were process-

Table 2

Mean Reaction Times and Percent Errors for Filler Trials in Experiment 1

\begin{tabular}{|c|c|c|c|c|c|c|}
\hline \multirow[b]{2}{*}{ Type of Filler Trial } & \multicolumn{2}{|c|}{ 250-msec SOA } & \multicolumn{2}{|c|}{ 550-msec SOA } & \multicolumn{2}{|c|}{ Mean } \\
\hline & RTs & Errors & RTs & Errors & RTs & Errors \\
\hline & 726 & & 699 & 4.37 & 712 & 6.56 \\
\hline Word prime-graphemically dissimilar $n$ & 716 & $5.76 \%$ & 690 & $4.10 \%$ & 703 & $4.93 \%$ \\
\hline Neutral control prime-nonword target & 730 & $5.00 \%$ & 713 & $5.00 \%$ & 721 & $5.00 \%$ \\
\hline
\end{tabular}


ing the prime and verifies that the paradigm was sufficiently sensitive to detect a facilitatory effect. The failure to obtain a rhyme priming effect when a semantic effect was obtained implies that the rhyme priming effect is not automatic.

Although semantic priming was obtained, significant inhibition for the words following unrelated primes was not obtained even at the long SOA, a finding that runs counter to the inhibitory effect reported by Neely (1977). Two explanations might be offered for the failure to find an inhibitory effect. First, it is possible that the subjects were not using a strategy of anticipating semantically related primes. Because of the different types of relationships between primes and targets, the subjects may have been discouraged from anticipating targets with a particular relationship to a prime. Since inhibitory effects have been interpreted as indicative of strategic processing, if the subjects were not using a target generation strategy, inhibition would not be expected. Second, Becker (1980) showed that an inhibitory effect would be obtained only if subjects were likely to generate a large number of potential targets based on the prime. He explained this result on the grounds that if subjects were comparing the unrelated target to the expected set of words, RTs would be slowed if the expected set was large and many comparisons had to be made. Reaction times might be minimally slowed or unaffected if subjects made only one comparison or even a few. In Experiment 1, in which the semantically related pairs were strong associates, the subjects may have been anticipating only one or a small set of words.

Two major differences between Hillinger's (1980) experiment and the present one might account for the differing results; both, however, would seem to have caused subjects to have had a greater tendency to use a rhyme generation strategy in Hillinger's experiment than the subjects had in this one. The first difference is that the stimulus set in our Experiment 1 contained semantically related items in addition to the phonologically related pairs. Because there were different types of relationships between the primes and targets, the subjects might have been less inclined to anticipate rhyming targets. Second, the subjects in Hillinger's experiment were required to make an overt lexical decision with respect to the prime prior to the presentation of the target. Forcing subjects to respond to the prime may have made them more aware of the relationships between the prime and target words and therefore resulted in greater use of strategies to anticipate targets.

\section{EXPERMENT 2}

In Experiment 2, we tested the idea that rhyme priming is strategically mediated, and investigated whether Experiment 1 failed to obtain rhyme priming because the inclusion of semantically related primes discouraged subjects from using a rhyme generation strategy. Thus, in Experiment 2, semantically related primes were not included. Also, the subjects were required to make a lexical decision in response to the prime in order to draw their attention to the relation between primes and targets.

In addition to these changes in experimental design, a manipulation was introduced to determine whether the size of the priming effect for graphemically dissimilar rhymes could be shown to be related to the likelihood that subjects, given the prime, could generate the target. Such a relationship might be expected if rhyme priming occurs because of conscious strategies. Previous evidence indicated that if subjects are asked to generate words that rhyme with a stimulus word, they are likely to generate graphemically similar rhymes (Donnenwerth-Nolan, Tanenhaus, \& Seidenberg, 1981). Consequently, one might predict that if a rhyme generation strategy underlies the rhyme priming effect, rhyme facilitation should be greater with graphemically similar pairs than for graphemically dissimilar pairs. However, in the data reported by Hillinger (1980), rhyme priming was equally as strong for the graphemically similar pairs as for the dissimilar ones. As discussed below, a possible explanation for equal facilitation from a rhyme generation strategy lies in the nature of the spelling-sound relationships of the graphemically dissimilar rhyming primes employed by Hillinger.

In order to choose target words that can be primed by either a graphemically similar or a graphemically dissimilar prime, there must be at least two spelling patterns that map onto the same phonological pattern. More often than not, groups of graphemically heterogeneous rhyming words consist of a large group of rhymes that are graphemically similar to each other (we will refer to these words as the common spelling-sound group) along with a small group of rhymes that do not share the graphemic features of the graphemically common words (we will refer to these words as the rare spelling-sound group). For example, for the set of rhymes consisting of cool, drool, fool, pool, rule, school, spool, stool, tool, yule, those having the -ool ending would constitute the common set and those with the -ule ending would constitute the rare set.

It is possible that the tendency to generate a graphemically similar rhyme depends on whether the prime is from the common or rare spelling-sound group. ${ }^{1}$ That is, if subjects see a prime from the rare group, they might have difficulty generating a graphemically similar rhyme and instead generate a word from the common group. ${ }^{2}$ If this is true, and if a rhyme generation strategy underlies the rhyme priming effect, then one should be able to manipulate the size of the effects by choosing prime-target pairs that are from either the common set or the rare set.

Looking at Hillinger's (1980) stimuli from the perspective of common and rare word groups, we found that nearly $90 \%$ of the primes in the graphemically dissimilar condition were from the rare spelling-sound group. ${ }^{3}$ Thus, it is possible that both the graphemically similar 
and graphemically dissimilar rhyme priming effects obtained by Hillinger could be attributed to a rhyme generation strategy.

A pretest performed on the word primes used in Experiment 2 confirmed the hypothesis that the tendency for subjects to generate a graphemically similar rhyme in response to a reference word was influenced by whether the prime was a common- or rare-group word. Twenty subjects were asked to generate one rhyming word for each of the primes. When the prime was from the common set, $90 \%$ of the generated rhymes were graphemically similar to the prime. However, when the prime was from the rare set, only $60 \%$ of the rhymes generated were graphemically similar.

In developing the stimulus materials, targets and primes from the common and rare spelling-sound pattern groups were selected. Consider the case for primes used in the graphemically dissimilar priming condition. If the prime was from the common group, the target was from the rare group. Upon seeing a prime from the common group, subjects ought very likely to have generated a rhyme from the common group and not to have generated the target. Thus, in this case priming ought not to have been seen for targets graphemically dissimilar to the prime. On the other hand, upon seeing a prime from the rare group, subjects ought to have been more likely to generate the target, since they would have been fairly likely to generate rhymes from the common group. Thus, in this condition, priming for graphemically dissimilar targets ought to have been seen. For the primes that were graphemically similar to the targets, priming ought to have been expected whether the prime and targets were from the common or from the rare group. However, the effect ought to have been stronger for words from the common set, given the pretest evidence.

It should be noted that in Experiment 2, the rare set targets tended to be lower in frequency than the common set targets (the median frequency of the common-word targets was 18 occurrences per million and the median frequency for rare words was 12 occurrences per million, based on Kučera \& Francis, 1967). However, this factor should have worked against the prediction above of no priming for the rare set targets in the graphemically dissimilar priming condition. There is some data indicating that phonological recoding is more likely to be employed with low than with high frequency words (Seidenberg et al., 1984). Consequently, according to Hillinger's proposal regarding the source of rhyme priming, one might have expected to see greater priming in the case of the rare set targets. Also, in studies of semantic priming, greater priming effects have been observed for low than for high frequency words (see, for example, Becker, 1979).

In sum, in Experiment 2, we tested the idea that Experiment 1 failed to yield rhyme priming effects because they are strategically mediated. The inclusion of seman- tically related primes may have discouraged the subjects from generating rhyme-related targets. If this analysis is correct, we ought to have observed rhyme priming effects in Experiment 2, in which semantically related items did not appear. In Experiment 2, we also tested whether strategically mediated rhyme priming effects in the graphemically dissimilar rhyming condition depended on the likelihood that subjects would generate the target as the primary rhyming associate of the prime. In Hillinger's (1980) experiment, the primes in the graphemically dissimilar rhyming condition were likely to be from the rarespelling group, whereas the targets were from the common group. If, in generating a rhyme based on the prime, subjects are more likely to generate a word that instantiates the common spelling of the rhyme priming dyad, then they would be likely to generate common-spelling targets that would be graphemically dissimilar from the rarespelling prime, and that would have produced the priming effect. If this analysis was correct, then rhyme priming in the graphemically dissimilar rhyme condition in Experiment 2 should have been greater for word targets from the common-spelling group than for word targets from the rare-spelling group. If on the other hand, rhyme priming in the graphemically dissimilar priming condition was more general and produced facilitation for a whole rhyme category and not just for a few primary rhyme associates of the prime, one should have observed similar priming effects for rare-spelling and common-spelling targets. In Experiment 2, we tested for these two alternatives.

\section{Method}

Design and Stimulus Materials. In order to create the rare set and common set word groups, 32 sets of four one-syllable rhyming words were selected from a rhyming dictionary (Reed, 1961). We chose each set by finding groups of graphemically heterogeneous rhymes in which there were a few rhymes (at least two) that were graphemically similar to each other yet were graphemically dissimilar from the majority of rhymes in that group. Two words from the common set of graphemically similar rhymes and two words from the rare set of graphemically similar thymes were chosen (e.g., HAIR, CHAIR; WEAR, SWEAR). One word from each of the two sets was designated as a target (e.g., HAIR and WEAR).

Each target could be preceded by one of four prime types: a graphemically similar rhyme (e.g., CHAIR-HAIR or SWEARWEAR), a graphemically dissimilar rhyme (e.g., SWEAR-HAIR or CHAIR-WEAR), an unrelated prime (e.g., EASE-HAIR or LOAD-WEAR), or a neutral control prime (See Appendix B for a list of all the primes and targets). Both sets of 32 targets were divided into four groups of eight words each. Four different stimulus sets were created according to a Latin square design, in order to determine which type of prime preceded the target words from each of the eight groups. Since each target rhymed with another target (its counterpart from the other graphemically similar group), the Latin square ensured that when one target was preceded by a phonemically similar prime, its ihyming counterpart target was preceded by either an unrelated or a neutral control prime (i.e., when HAIR was primed by CHAIR or SWEAR, WEAR was primed by either an unrelated word or the neutral control).

In addition to the prime-target relationships of interest described above, the present experiment employed all of the other types of 
prime-target relationships that were included in Experiment 3 of Hillinger's study. These included graphemically similar-phonemically dissimilar word pairs, word primes followed by phonemically similar nonword targets, word primes followed by graphemically dissimilar nonword targets, nonword primes followed by nonword targets, nonword primes followed by word targets, and neutral control primes followed by nonword targets. Fifteen examples of each of these types of pairs were constructed. Unlike the targets in the filler trials in Experiment 1, these targets and those for the remaining three experiments in this paper were not counterbalanced across subjects. Consequently, it is not possible to interpret differences among responses to these different types of filler items.

All the nonwords were created by changing one or two letters of a word and were judged to be both pronounceable and orthographically acceptable. These same nonwords were used in both Experiment 2 and Experiment 3. In Experiment 2 through 5, both primes and targets were presented in uppercase letters.

Procedure. All aspects of the procedure for Experiment 2 were the same as those in Experiment 1, with one exception. One second after a subject initiated a trial, two plus signs were presented at the center of the computer screen, one above the other. After $1 \mathrm{sec}$ the top plus sign was replaced with the prime. Each subject was told to indicate as quickly and as accurately as possible whether the prime was a real English word or a nonword; each subject was instructed to respond "nonword" to the neutral control prime. After the subject responded to the prime, the prime was erased from the screen. A pause of $\mathbf{4 0} \mathrm{msec}$ followed the subject's response to the prime before the bottom plus sign was replaced by the target; this 40 -msec pause was included to allow the subjects enough time to remove their finger from the response key after responding to the prime. The subjects were instructed to indicate as quickly and as accurately as possible whether the target was a real English word or a nonword. This procedure was also used in Experiments 3 and 5 ; its description will therefore not be repeated.

Subjects. Twenty-four Rice University undergraduates participated in Experiment 2 in order to fulfill a class requirement. Each subject was randomly assigned to one of the four cells of the Latin square, which determined what type of prime would precede a given target. None of these subjects had participated in the rhyme generation pretest.

\section{Results}

Two target words, TRYST and TYKE, were incorrectly classified as nonwords by $75 \%$ and $58 \%$ of the subjects, respectively. Therefore, these trials, as well as the trials based on the common set counterparts of TRYST and TYKE (FIST and BIKE) were eliminated from the analysis.

An examination of the mean RTs in Table 3 reveals that in all cases, the RTs in response to the targets that were preceded by rhyming primes, whether graphemically similar or graphemically dissimilar, were faster than the RTs in response to the neutral controls. These differences were significant for RTs in the analysis by subjects $[F(1,23)$
$=8.51, M S e=6,419, p=.008$, and $F(1,23)=4.61$, $M S e=7,121, p=.04]$ and by items $[F(1,58)=15.33$, $M S e=4,025, p=.002$, and $F(1,58)=5.16, M S e=$ $4,238, p=.03$ ], for the graphemically similar rhymes and for the graphemically dissimilar rhymes, respectively. However, it is also evident that RTs in the unrelated prime condition were faster than those in the neutral control condition $[F(1,23)=4.24, M S e=7,121, p=.05$ by subjects, and $F(1,58)=5.31, M S e=5,457, p=.02$ by words]. Although more errors were made in response to the targets preceded by the unrelated prime than in response to those preceded by the neutral control, this effect was not significant for either of the analyses (both $F_{\mathrm{s}}<1.0$ ).

Neutral control primes have been employed in lexical decision experiments because unrelated primes may cause inhibition if subjects use a strategy of generating words related to a prime and compare the target to this generated set (Neely, 1977; but see Patton \& Lefton, 1985). The neutral control condition is thought to produce better baseline RTs, since nothing can be generated in response to the neutral control prime. It is clear that in the present experiment there was facilitation rather than inhibition in the responses to unrelated primes. For reasons to be presented in the Discussion, it was felt that in the present experiment, the unrelated prime condition would provide a better baseline.

If the unrelated prime condition is used as the control condition, then no facilitation in RTs or reduction in error rates was found for targets primed by either type of rhyme in either the analysis by subjects or the analysis by words ( $M S \mathrm{Se}=3,892$ in the analysis of RTs by subjects, and $M S e=115$ in the analysis of errors by subjects, all $p s>.10$ ). Also, the effect of prime type failed to interact with the set-size manipulation in both the subject and item analyses for RTs and errors (all $p s>.20$ ).

There was a significant main effect for target set size in the RT analysis. Targets from the common set were responded to faster than targets from the rare set $[F(1,23)$ $=12.32, \mathrm{MSe}=4,005, p=.002$ by subjects]. This effect was not significant in the analysis by words, though $[F(1,58)=2.78, M S e=16,809, p=.10]$. Faster responses to common set targets are not surprising, however, since the common set words tended to be the more frequent words as well. Set size did not influence the error percentages in either of the analyses (both $F$ s $<1.0$ ).

The responses to the filler trials are presented in Appendix $C$. The pattern of responses to these filler items is in many ways similar to the pattern of responses ob-

Table 3

Mean Reaction Times and Percent Errors for Experiment 2

\begin{tabular}{lccccc}
\hline & \multicolumn{2}{c}{ Common Set Targets } & & \multicolumn{2}{c}{ Rare Set Targets } \\
\cline { 2 - 3 } \cline { 5 - 6 } \multicolumn{1}{c}{ Type of Prime } & RTs & Errors & & RTs & Errors \\
\hline Graphemically similar rhymes & 538 & $3.12 \%$ & & 579 & $5.56 \%$ \\
Graphemically dissimilar rhymes & 553 & $5.38 \%$ & & 595 & $4.69 \%$ \\
Unrelated & 563 & $6.08 \%$ & 578 & $9.03 \%$ \\
Neutral control & 591 & $3.47 \%$ & 621 & $7.99 \%$ \\
\hline
\end{tabular}


served in Hillinger's Experiment 3. Specifically, error percentages were high when a nonword was preceded by a graphemically similar word prime. Also, the RTs for responses to target words preceded by a graphemically similar yet phonemically dissimilar word were comparable to the RTs observed in the word-target comparison trials.

\section{Discussion}

Even though its procedure was closer to that employed by Hillinger (1980), Experiment 2 failed to reveal any clear rhyme priming effect (in comparison with unrelated word-word trials), irrespective of the size of the available pool of graphemically similar or dissimilar thymes. However, the results were complicated by the finding that the RTs when targets followed the neutral control were longer than the RTs when targets followed an unrelated word. It is possible that the frequency with which words followed word primes compared to the frequency with which words followed the neutral control might have caused this pattern. In Experiment 2 (as well as in the original Hillinger experiment), a word target was twice as likely as was a nonword target to follow a word prime. Word targets and nonword targets were equally likely to follow neutral control primes. Thus, the subjects might have been biased to respond "word" following a word prime, which would have resulted in faster RTs for such trials than for those in which targets were preceded by the neutral control. One might object that if this bias were operating, then RTs in response to nonwords following word primes should be longer than RTs in response to nonwords following the neutral control. The filler trial data in Appendix $\mathrm{C}$ shows that although error rates were higher for nonwords preceded by words than for nonwords preceded by the neutral control, the RTs were slightly faster. However, the same nonword targets did not appear across the different priming conditions, and thus any differences should not be accorded much weight in attempting to explain the results.

Collapsing across rare and common set targets, the word targets following an unrelated prime were responded to $35 \mathrm{msec}$ faster than were words following a neutral control prime. It is possible that this large advantage for words preceded by word primes may have masked any facilitation in RTs relative to the control condition due to a rhyme generation strategy. Although Hillinger (1980) was able to find significant rhyme priming effects even though his experiment contained the same confound, the failure to replicate his effects might be more compelling if this confound were eliminated. In Experiment 3, the proportion of word targets and the proportion of nonword targets following the different types of primes were closely matched.

There was also some suggestion in the error data that the bias to respond "word" following a word prime was exaggerated if the prime and target were visually similar. Error rates in responses to word targets preceded by graphemically similar rhymes $(4.34 \%)$ or by graphemi- cally similar nonrhymes $(3.61 \%)$ were slightly lower than they were for the other word-target conditions, while the error rate in responses to a nonword preceded by a graphemically similar word was much higher (13.89\%) than it was for the other nonword-target conditions. The relative frequencies with which visually similar primetarget pairs contained a word target as compared to a nonword target may also have been at work here. There were twice as many trials containing a word target as there were containing a nonword target in which the prime and target differed by only a single letter. ${ }^{4}$ In order to ensure that any facilitation in response to graphemically similar rhymes that might be observed in Experiment 3 could not be attributed to graphemic rather than phonological similarity, the number of visually similar prime-target pairs containing a word target was matched approximately with the number containing a nonword target.

\section{EXPERIMENT 3}

\section{Method}

Design and Stimulus Materials. Experiment 3 was identical to Experiment 2, with the following exceptions: Ninety additional filler trials were added to the stimulus set. Of these 90 trials, 15 were graphemically similar word-prime-nonword-target pairs, 15 were graphemically dissimilar word-prime-nonword-target pairs, 30 were graphemically dissimilar nonword-prime-nonword-target pairs, and 30 were graphemically dissimilar nonword-prime-word-tárget pairs. The result was a total of 63 word-word trials, 61 nonword-word trials, and 60 each of the nonword-nonword and word-nonword trials. There were a total of 31 word-word trials, and 30 wordnonword trials in which the prime and target were visually similar (i.e., differed by only the first letter).

The trials containing the targets TRYST and TYKE and their common set counterparts were eliminated from the stimulus set. These trials were replaced with more familiar words (see Appendix B).

Subjects. Thirty-two Rice University graduate students participated in this experiment. None were psychology graduate students, and none were familiar with the focus of this research. All subjects were paid \$2.00 for one half hour of participation.

\section{Results}

Unlike in Experiment 2, in Experiment 3 there was no significant difference between the responses made to the neutral-control-prime-word-target pairs and to the targets preceded by the unrelated primes, in either RTs or error percentages in the analyses by subjects or by words (see Table 4).

Of interest in Experiment 3 was the main effect of type of prime and the interaction between type of prime and the set manipulation. No significant differences were observed for this main effect or this interaction, in either the analysis by subjects or the analysis by words, in both RTs and error percentages (all $F \mathrm{~S}<1.0$ ). The only difference that approached significance was the RT difference between the common set targets and the rare set targets. Common set targets tended to be identified as words faster than rare set targets did [603 msec vs. $616 \mathrm{msec}$; $F(1,31)=4.02, M S \mathrm{e}=2,863, p=.053$ by subjects $]$. 
Table 4

Mean Reaction Times and Percent Errors for Experiment 3

\begin{tabular}{|c|c|c|c|c|}
\hline \multirow[b]{2}{*}{ Type of Prime } & \multicolumn{2}{|c|}{ Common Set Targets } & \multicolumn{2}{|c|}{ Rare Set Targets } \\
\hline & RTs & Errors & RTs & Errors \\
\hline Graphemically similar thymes & 597 & $5.08 \%$ & 610 & $3.91 \%$ \\
\hline Graphemically dissimilar rhymes & 614 & $4.30 \%$ & 631 & $3.12 \%$ \\
\hline Unrelated & 595 & $5.47 \%$ & 619 & $3.21 \%$ \\
\hline Neutral control & 607 & $4.69 \%$ & 606 & $5.08 \%$ \\
\hline
\end{tabular}

This effect failed to be significant in the analysis by words $(F<1.0)$.

The responses made to the filler trials are presented in Appendix C. The error rates in responses to nonwords preceded by graphemically similar words were again the highest of the nonword error rates, although the difference was less than that observed in Experiment 2 and similar to that observed in Experiment 1.

\section{Discussion}

The results of Experiment 3 replicated those of Experiment 2 in failing to demonstrate any facilitation in lexical decisions based on phonological similarity of primes and targets. There were two clear differences between the pattern of results in this experiment and in the previous one: (1) the elimination of the facilitation for unrelated primes, relative to the neutral control, and (2) a reduction in the error rates for the nonword targets preceded by the visually similar word primes. Thus, changes in the proportion of trials in the different conditions evidently sufficed to eliminate or reduce the response biases hypothesized to be operating in Experiment 2.

Experiments 1 to 3 of this paper were conducted in an attempt to discern whether facilitation due to phonological similarity is the result of conscious or automatic processes. In none of these experiments was phonological facilitation observed either in RTs or error percentages. The question remained as to the source of Hillinger's (1980) observed results. The design and procedure in Experiment 3 were quite similar to those used by Hillinger, although the stimuli were different. It was possible that the stimuli used by Hillinger differed in some important respect from those we had employed (e.g., in the proportion of words with irregular spelling-sound correspondences) and thus led to rhyme priming for Hillinger's stimuli and not ours. Rather than attempt to test various possibilities, we thought it wise first to try to replicate Hillinger's rhyme priming effects by using his stimuli.

In our Experiment 4, the words that had been used in Hillinger's (1980) Experiments 2 and 3 were employed, along with an SOA manipulation similar to that used in our Experiment 1 . Assuming that the rhyme priming effects were obtained, we wished to determine whether they would appear at the short SOA, indicating an automatic effect, or only at the long SOA, indicating a strategic effect.

\section{EXPERIMENT 4}

\section{Method}

Design and Stimulus Materials. Experiment 4 consisted of the same 100 trials as were employed in Hillinger's (1980) Experiment 3 . Of concern were the RTs in response to 50 word-target trials that were incorporated into a Latin square design. The 50 trials were divided into five groups of 10 targets each. All targets in each group were preceded by the same type of prime. The same five target groups appeared in each of five stimulus sets, but in each set, they were preceded by a different type of prime. Across all five stimulus sets, each target group was preceded by each type of prime.

The five types of primes included graphemically similar rhymes, graphemically dissimilar rhymes, unrelated word primes, nonword primss, and neutral control primes. In addition to the 50 comparison trials, 50 filler trials were presented. All subjects saw the same set of filler trials. These 50 trials consisted of 10 each of the following types: word prime-nonword target (FAME-RALL); nonword prime-nonword target (COFF-TULD); graphemically similar word prime-nonword target (MANE-FANE); graphemically similar, phonemically dissimilar word prime-word target (LEMON-DEMON); and neutral prime-nonword target (*****-PLINT). For these filler trials, the same nonword targets did not appear in the different conditions, and the word targets for the LEMON-DEMON type pairs did not appear in any other condition and were not matched in any way to other word targets. Therefore, as in Experiments $\mathbf{2}$ and 3, there were no controls against which to assess the RTs for these filler items.

All the prime-target pairs were precisely those used by Hillinger (1980), with the exception of 10 word-nonword filler trials that were not provided in his appendix. The trials were presented in a different random order for each subject. Also, each subject performed 30 practice trials before beginning Experiment 4 . The practice-trial stimuli were not the same as those employed by Hillinger, because these were not supplied in the appendix of his original paper either.

The subjects were randomly assigned to one of two SOA conditions. The subjects in one of these groups were given a $250-\mathrm{msec}$ SOA between presentation of the prime and the target, whereas the subjects in the other group were given a 1,000-msec SOA.

Subjects. Thirty Rice University undergraduates participated in Experiment 4 in order to fulfill a class requirement. Each subject was randomly assigned to one of the stimulus set groups and one of the SOA groups.

\section{Results}

The main effect for type of prime was not significant in the analysis of RTs either by subjects $[F(4,112)=1.19$, $M S e=2,152, p=.32]$ or by words $[F(4,196)=.50$, $M S e=15,225]$. Also, type of prime failed to interact significantly with the SOA manipulation in these analyses (both $F \mathrm{~s}<1.0$ ). 
Table 5

Mean Reaction Times and Percent Errors for Experiment 4

\begin{tabular}{|c|c|c|c|c|c|c|}
\hline \multirow[b]{2}{*}{ Type of Prime } & \multicolumn{2}{|c|}{ 250-msec SOA } & \multicolumn{2}{|c|}{$1,000-\mathrm{msec}$ SOA } & \multicolumn{2}{|c|}{ Mean } \\
\hline & RTs & Errors & RTs & Errors & RTs & Errors \\
\hline Graphemically similar rhymes & 567 & $4.67 \%$ & 591 & $4.67 \%$ & 579 & $4.67 \%$ \\
\hline Graphemically dissimilar rhymes & 589 & $6.67 \%$ & 596 & $8.67 \%$ & 593 & $7.67 \%$ \\
\hline Unrelated & 576 & $5.33 \%$ & 570 & $3.33 \%$ & 573 & $4.33 \%$ \\
\hline Nonword & 579 & $8.67 \%$ & 611 & $6.67 \%$ & 595 & $7.67 \%$ \\
\hline Neutral control & 578 & $4.67 \%$ & 585 & $3.33 \%$ & 582 & $4.00 \%$ \\
\hline
\end{tabular}

In neither of the analyses of error percentages was there a significant effect due to the type of prime (MSe $=57$ by subjects and $M S e=208$ by words, both $p s>.10$ ). The error percentages for both the neutral control and the unrelated prime conditions were lower than those observed in either of the rhyming prime conditions (see Table 5).

\section{Discussion}

In Experiment 4, there was no evidence of rhyme priming. When collapsed across SOA, the graphemically similar targets were responded to $3 \mathrm{msec}$ faster than the neutral control targets, and the graphemically dissimilar targets were responded to $11 \mathrm{msec}$ slower.

This failure of these first four experiments to demonstrate phonological priming raises questions concerning the original study by Hillinger (1980), a study that contains the only reported evidence of significant rhyme priming with successive prime-target presentation, and the only reported evidence of priming with graphemically dissimilar primes. In Experiment 5, the original Experiment 3 reported by Hillinger was replicated as precisely as possible: the subjects were required to respond to the prime before the target word appeared. In this replication, we employed almost twice as many subjects as Hillinger did in his original study.

\section{EXPERIMENT 5}

\section{Method}

Design and Stimulus Materials. Experiment 5 employed one between-subjects factor, the assignment of targets to priming condition according to a Latin square design. In addition, type of prime was varied within subjects. All remaining aspects of Experiment 5 were identical to those of Experiment 4, with the following exception: all subjects were required to respond to the prime prior to the presentation of the target. This procedure has been described in the method section for Experiment 2 and will not be repeated here.

Subjects. Forty-five Rice University undergraduates participated in Experiment 5 in order to fulfill a class requirement. Each subject was randomly assigned to one of the stimulus set groups.

\section{Results}

The effect of prime-target relationship was not significant in the analysis of RTs by subjects $[F(4,176)=1.00$, $M S \mathrm{e}=3,258, p=.40]$ or by items $[F(4,196)=.85$, $M S \mathrm{e}=6,488, p=.49]$. The same was true with regard to the percentage of errors by subject $[F(4,176)=.86$, $M S e=39, p=.48]$ and by items $[F(4,196)=.69$,
$M S e=55, p=.60]$. The graphemically similar and graphemically dissimilar rhyming conditions were both individually compared to the neutral control. These analyses found no significant differences in RTs or error percentages in either the analyses by subjects or the analyses by items (all $p s>.20$ ).

The data presented in Table 6 reveal that the responses were faster to the targets preceded by an unrelated prime than in any of the other conditions. An individual comparison of the unrelated condition against the neutral control condition found that this difference approached conventional levels of significance by subjects $[F(1,44)=$ $3.05, M S \mathrm{e}=3,390, p=.087]$ but not by words $[F(1,49)$ $=1.73, p=.200]$.

Inspection of the filler trials (see Appendix $\mathrm{C}$ ) reveals a pattern similar to what was observed by Hillinger (1980). The errors due to graphemically similar word prime-nonword target trials are inflated. This effect is comparable to what was observed in Experiment 2 of this paper and Experiment 3 of Hillinger's paper.

\section{Discussion}

This replication failed to produce any evidence of phonological facilitation, with respect to either graphemically similar or graphemically dissimilar prime-target relationships. Contrary to the data and conclusions offered by Hillinger, our data do not provide any evidence of rhyme priming.

\section{GENERAL DISCUSSION}

The initial intent of this study was to determine whether automatic spreading activation occurred on the basis of phonological similarity in a phonological lexicon. Previous evidence showing priming for words preceded by graphemically dissimilar rhyming words did not provide unequivocal support for this contention, because the priming might have been due to subject strategies. Table 7 presents a summary of the results of the five experiments

Table 6

Mean Reaction Times and Percent Errors for Experiment 5

\begin{tabular}{lll}
\multicolumn{1}{c}{ Type of Prime } & RTs & Errors \\
\hline Graphemically similar rhymes & 578 & $4.00 \%$ \\
Graphemically dissimilar rhymes & 587 & $5.33 \%$ \\
Unrelated & 568 & $2.89 \%$ \\
Nonword prime & 579 & $4.00 \%$ \\
Neutral control & 589 & $3.78 \%$ \\
\hline
\end{tabular}


Table 7

Facilitation in Reaction Times for Word Targets Preceded by Rhyming Primes Relative to Neutral Control and Unrelated Prime Conditions

\begin{tabular}{|c|c|c|c|c|c|c|}
\hline & \multicolumn{2}{|c|}{ Graphemically Similar } & \multicolumn{2}{|c|}{ Graphemically Dissimilar } & \multicolumn{2}{|c|}{ Baseline RTs } \\
\hline & Neutral & Unrelated & Neutral & Unrelated & Neutral & Unrelated \\
\hline \multicolumn{7}{|c|}{ Experiment 1} \\
\hline 250-msec SOA & +15 & +27 & +1 & +13 & 625 & 637 \\
\hline 550-msec SOA & +7 & -3 & +19 & +9 & 613 & 603 \\
\hline Mean & +11 & +12 & +10 & +11 & 619 & 620 \\
\hline \multicolumn{7}{|c|}{ Experiment 2} \\
\hline Common set & +53 & +25 & +38 & +10 & 591 & 563 \\
\hline Rare set & +42 & -1 & +26 & -17 & 621 & 578 \\
\hline Mean & $+48^{*}$ & +13 & $+32 *$ & -3 & 606 & 571 \\
\hline \multicolumn{7}{|c|}{ Experiment 3} \\
\hline Common set & +10 & -2 & -7 & -19 & 607 & 595 \\
\hline Rare set & -4 & +9 & -25 & -12 & 606 & 619 \\
\hline Mean & +3 & +3 & -16 & -16 & 607 & 607 \\
\hline \multicolumn{7}{|c|}{ Experiment 4} \\
\hline 250-msec SOA & +11 & +9 & -11 & -13 & 578 & 576 \\
\hline 1,000 -msec SOA & -6 & -21 & -11 & -26 & 585 & 570 \\
\hline Mean & +3 & -6 & -11 & -20 & 582 & 573 \\
\hline \multicolumn{7}{|c|}{ Experiment 5} \\
\hline Mean & +11 & -10 & +2 & -19 & 589 & 568 \\
\hline
\end{tabular}

*Difference significant at the $p<.05$ level; however, RTs for unrelated primes were also significantly faster than for neutral controls (see Experiment 2).

reported here, in terms of facilitation in RTs for words preceded by graphemically similar or graphemically dissimilar rhyming primes. Because of the concerns raised by Jonides and Mack (1984) about the use of a neutral control prime, facilitation is shown relative to both the neutral control and the unrelated word conditions. As discussed in Experiment 2, significant facilitation was obtained for both types of rhyming primes relative to the neutral control condition; however, the RT for targets preceded by unrelated primes was also significantly faster than in the neutral control condition. Relative to the unrelated condition, no significant priming was observed.

Despite the general lack of significant facilitation, it is possible that small but consistent effects might be observed across experiments. In the case of targets preceded by graphemically dissimilar rhymes at the short SOA, at which automatic priming might have been expected to be observed, a 1-msec facilitation was obtained in Experiment 1 and an 11-msec inhibition in Experiment 4, relative to the neutral control prime, and a $13-\mathrm{msec}$ facilitation in Experiment 1 and a 13-msec inhibition in Experiment 4, relative to the unrelated condition. In the other experiments, in which subjects would have had time to use a rhyme generation strategy, the mean facilitation across conditions for graphemically dissimilar rhyming primes was negative more often than positive. Thus, priming for graphemically dissimilar rhymes could hardly be said to be automatic or under subject control, since it was not observed. Of course, these experiments do not rule out the possibility that strategically mediated priming for graphemically dissimilar rhymes could be obtained, under experimental conditions designed to maximize both the likelihood that subjects would adopt a rhyme generation strategy and the probability that the generated rhymes would match the targets. Experiments testing this possibility might be of some interest in determining the effects of expectations on the word-recognition process; however, they would not bear on the question of automatic spreading activation.

Since the priming for graphemically dissimilar rhymes was one of the main pieces of evidence used to rule out an encoding-bias interpretation of the facilitation for graphemically similar rhymes, one might wonder whether the encoding-bias hypothesis is now on firmer ground. However, while these experiments failed to demonstrate the priming for graphemically dissimilar rhymes that had been demonstrated by Hillinger, they also failed to demonstrate the priming for graphemically similar rhymes that had been reported by other investigators (Meyer et al., 1974; Shulman et al., 1978). Table 7 shows that the facilitation for graphemically similar rhymes was generally positive, but that the magnitudes of the positive effects were quite small. Aside from the Hillinger study, the only study to report significant priming for graphemically similar rhyming words used simultaneous presentation of twoletter strings (Shulman et al., 1978). ${ }^{5}$ In the two experiments reported by Meyer et al. (1974), a facilitation of $21 \mathrm{msec}$ for graphemically similar rhymes was obtained in one experiment, using simultaneous presentation, and a 16-msec facilitation was obtained in another experiment, using sequential presentation; but the facilitation was not significant in either case.

The failure in the present experiments to find significant priming for graphemically similar rhymes might lead to one of two conclusions: First, as Hillinger (1980) suggested, it may be that encoding bias only becomes evident in a procedure that presents the two words simultaneously so as to highlight their graphemic similarity (see 
Bradshaw \& Nettleton, 1974, for supporting evidence from a pronunciation task). A recent study by Seidenberg et al. (1984) also suggests that there must be several words within the presentation list that are pronounced like the more regular of the graphemically similar nonrhyming pairs in order for the bias to develop. Thus, encoding bias may only develop under a special set of circumstances that did not hold in the present experiments. The second possibility, as argued by Meyer et al. (1974), is that encoding bias may only speed the recognition of the second word if this second word has more than one possible phonemic recoding, according to the rules of grapheme-tophoneme conversion. It is possible that, in the present experiment, there was an insufficient number of target words with more than one possible phonemic recoding to observe significant facilitation. ${ }^{6}$

Although the present experiments do not provide strong evidence for or against the encoding-bias hypothesis, they do refute the claim that automatic spreading activation occurs on the basis of phonological similarity during visual word recognition. However, they do not rule out the existence of a phonological lexicon separate from a conceptual network. Other evidence supports such a separation. Neurologically impaired individuals have been reported who show an ability to read many words aloud (including words with irregular letter-sound correspondences), despite showing no evidence of understanding the meaning of these words (Bub, Cancelliere, \& Kertesz, 1985; Schwartz, Saffran, \& Marin, 1980). Also, a patient has been reported who understood the meaning of visually presented words yet showed no evidence of knowledge of the words' phonological representations (Caramazza, Berndt, \& Basili, 1983). These data could be explained if there were separate phonological and semantic lexicons that could be differentially affected by brain damage.

Assuming that a separate phonological lexicon exists, the failure to find rhyme priming with visual presentation might indicate either that this lexicon is not organized so that spreading activation can occur, or that this lexicon is not activated during visual word recognition. One means of deciding between these alternatives would be to investigate whether automatic rhyme priming occurs in auditory word recognition. If rhyme priming is not obtained even with auditory presentation, one will have to abandon the notion of automatic spreading activation based on phonological similarity. If rhyme priming could be obtained with auditory presentation but not with visual presentation, this would constitute further evidence that visual word recognition does not depend on accessing a phonological representation.

\section{REFERENCES}

Bauer, D. W., \& Stanovich, K. E. (1980). Lexical access and the spelling-to-sound regularity effect. Memory \& Cognition, 8, 424-432. BECKER, C. A. (1979). Semantic context and word frequency effects in visual word recognition. Journal of Experimental Psychology: Human Perception \& Performance, 5, 252-259.

BeCKer, C. A. (1980). Semantic context effects in visual word recog- nition: An analysis of semantic strategies. Memory \& Cognition, $\mathbf{8}$, 493-512.

BESNER, D., \& DAVELAAR, E. (1983). Suedo-homofoan effects in visual word recognition: Evidence for phonological processing. Canadian Joumal of Psychology, 37, 300-305.

Bradshaw, J. L., \& NetTleton, N. C. (1974). Articulatory interference and the MOWN-DOWN heterophone effect. Journal of Experimental Psychology, 102, 88-94.

Bub, D., Cancelliere, A., Kertesz, A. (1985). Whole-word and analytic translation of spelling to sound in a non-semantic reader. In K. E. Patterson, J. C. Marshall, \& M. Coltheart (Eds.), Surface dyslexia. London: Erlbaum.

Caramazza, A., Berndt, R. S., \& Basili, A. (1983). The selective impairment of phonological processing: A case study. Brain \& Language, 18, 128-174.

Collins, A. M., Loftus, E. F. (1975). A spreading activation theory of semantic processing. Psychological Review, 82, 407-428.

Coltheart, M. (1978). Lexical access in simple reading tasks. In G. Underwood (Ed.), Strategies of information processing (pp. 151216). London: Academic Press.

Coltheart, M., Davelaar, C., Jonasson, J., \& Besner, D. (1977). Access to the internal lexicon. In S. Dornic (Ed.), Attention and performance, II (pp. 535-555). New York: Academic Press.

Donnenwerth-Nolan, S., Tanenhaus, M. K., \& Seidengerg, M. (1981). Multiple code activation in word recognition: Evidence from rhyme monitoring. Journal of Experimental Psychology: Human Learning \& Memory, 7, 170-180.

EvetT, L. J., Humphries, G. W. (1981). The use of abstract graphemic information in lexical access. Quarterly Joumal of Experimental Psychology, 33, 325-350.

FORSTER, K. I. (1976). Accessing the mental lexicon. In R. J. Walker \& F. Wales (Eds.), New approaches to language mechanisms (pp. 257-287). Amsterdam: North-Holland.

HiLlinger, M. L. (1980). Priming effects with phonemically similar words: The encoding-bias hypothesis reconsidered. Memory \& Cognition, 8, 115-123.

Humphrey, G. W., Evett, L. J., \& Taylor, D. E. (1982). Automatic phonological priming in visual word recognition. Memory \& Cognition, 10, 576-590.

JoNIDES, J., \& MACK, R. (1984). On the cost and benefit of cost and benefit. Psychological Bulletin, 96, 29-44.

KePPEL, G., \& STRAND, B. Z. (1970). Free-association responses to the primary purposes and other responses selected from the PalermoJenkins norms. In L. Postman \& G. Keppel (Eds.), Norms of word association (pp. 177-239). New York: Academic Press.

KuČera, H., \& FranCIs, W. N. (1967). Computational analysis of present day American English. Providence, RI: Brown University Press.

MARTIN, R. C. (1982). The pseudohomophone effect: The role of visual similarity in non-word decisions. Quarterly Journal of Experimental Psychology, 34A, 395-409.

Meyer, D. E., Schvaneveldt, R. W., Ruddy, M. G. (1974). Functions of graphemic and phonemic codes in visual word-recognition. Memory \& Cognition, 2, 309-321.

MYERs, J. (1979). Fundamentals of experimental design (3rd ed.). Boston: Allyn and Bacon.

NEELY, J. H. (1976). Semantic priming and retrieval from lexical memory: Evidence for facilitatory and inhibitory processes. Memory \& Cognition, 4, 648-654.

NeELY, J. H. (1977). Semantic priming and retrieval from lexical memory: Roles of inhibitionless spreading activation and limitedcapacity attention. Journal of Experimental Psychology, 106, 226-254.

PARKIN, A. J., \& Underwood, G. (1983). Orthographic vs. phonological irregularity in lexical decision. Memory \& Cognition, 11, 351-355.

Patterson, K., Marcel, A. J. (1977). Aphasia, dyslexia, and the phonological coding of written words. Quarterly Joumal of Experimental Psychology, 29, 307-18.

Patton, B. L., Lefton, L. A. (1985). Facilitation without inhibition. Bulletin of the Psychonomic Society, 23, 191-194.

Posner, M. I., \& SNyder, C. R. R. (1975). Facilitation and cognitive 
control. In R. L. Solso (Ed.), Information processing and cognition: The Loyola Symposium (pp. 55-85). Hillsdale, NJ: Erlbaum.

REED, L. (1961). The writer's rhyming dictionary. Boston: The Writer, Inc.

Schwartz, M., Saffran, E., Marin, O. S. M. (1980). Fractionating the reading process in dementia: Evidence for word-specific printto-sound associations. In M. Coltheart, K. E. Patterson, \& J. Marshal (Eds.), Deep dyslexia (pp. 259-269). London: Routledge \& Kegan Paul.

Seidenberg, M. S., Waters, G. S., Barnes, M. A., \& Tanenhaus, M. K. (1984). When does irregular spelling or pronunciation influence word recognition? Journal of Verbal Learning \& Verbal Behavior. 23, 383-404.

Shulman, H. G., Hornak, R., \& Sanders, E. (1978). The effects of graphemic, phonetic, and semantic relationships on access to lexical structures. Memory \& Cognition, 6, 115-123.

TAFT, M. (1982). An alternative to grapheme-phoneme conversion rules? Memory \& Cognition, 10, 465-474.

Tanenhaus, M. K., Flanigan, H. P., Seidenberg, M. S. (1980). Orthographic and phonological activation in auditory and visual word recognition. Memory \& Cognition, 8, 513-520.

\section{NOTES}

1. By using the word rare we do not mean to imply that these words are either infrequent or have irregular grapheme-to-phoneme correspondences. For example, the words group and wear are from the rare spelling-sound group but are fairly frequent words. Also the words claim and soak are rare spelling-sound words but have predictable pronunciations.

2. It is not necessarily the case that a subject must actually generate the target in order to facilitate target identification. For example, features of Forster's (1976) peripheral access file model would predict that subjects may speed target identification by generating words within the same spelling-sound group as the target. In Forster's model, words from the same spelling-sound group would be closer to each other in the graphemic access file than words from other spelling-sound groups. Thus, if the search for the target began with the access file entry for the expected word, the entry for a target graphemically similar to the expected word could be located faster than for a graphemically dissimilar word, leading to faster RTs.

3. Of the $\mathbf{5 0}$ graphemically dissimilar rhyming prime-target pairs used by Hillinger, the spelling-sound group membership could be determined for only 39 pairs ( 11 pairs could not be considered, because at least one member of the pair was a plural form and/or the words were not true rhymes-e.g., there is a diphthong in the target STEW but not in the prime SHOE). Of the remaining 39 pairs, there were 32 cases in which the target was a member of the common spelling-sound group and only 4 cases where the prime was a member of the common spelling-sound group. In 3 cases, both prime and target were from spelling-sound groups of the same size. These numbers were computed from Reed (1961).

4. It should be pointed out here that Hillinger's Experiment 3 also contained a disproportionate number of graphemically similar word trials following word primes. In Experiment 1 of the present paper, such a disparity was not present. In Experiment 1 the errors made in response to the graphemically similar word-nonword pairs $(6.56 \%)$ were lower than what was observed both in Hillinger's Experiment $3(24.8 \%)$ and in Experiment 2 of the present paper (13.9\%).

5. Evett and Humphries (1981) and Tanenhaus, Flanigan, and Seidenberg (1980) also found priming for visually similar thymes. Importantly, in both of these papers the researchers were able to attribute the effect to visual similarity, since visually similar nonthyming pairs also produced the effect. These experiments, however, utilized the perceptual identification task and the Stroop color-naming task, respectively.

6. Since the encoding-bias hypothesis was not the focus of the present experiments, the experiments were not designed to obtain a critical piece of evidence concerning it. Although graphemically similar, phonemically dissimilar prime-target pairs were included in some of these experiments, the targets did not appear in the baseline condition, and thus no meaningful assessment of facilitation or inhibition could be made.

APPENDIX A

Words Used in Experiment 1

\begin{tabular}{lllll}
\hline Target & $\begin{array}{c}\text { Phonemically Similar- } \\
\text { Graphemically Similar }\end{array}$ & $\begin{array}{c}\text { Phonemically Similar- } \\
\text { Graphemically Dissimilar }\end{array}$ & $\begin{array}{c}\text { Semantically } \\
\text { Related }\end{array}$ & Unrelated Control \\
\hline spool & FOOL & RULE & THREAD & WALTZ \\
grave & CRAVE & WAIVE & TOMB & VANE \\
die & PIE & FLY & LIVE & TREAD \\
rose & NOSE & TOES & BUD & SPOKE \\
round & POUND & DOWNED & EARTH & OUGHT \\
chair & FAIR & MARE & ARM & RISK \\
take & MAKE & ACHE & GIVE & ROAST \\
gun & PUN & ONE & SHOT & BOUND \\
field & YIELD & PEALED & BATTLE & EIGHT \\
feet & MEET & SEAT & SHOE & POEM \\
good & HOOD & SHOULD & BAD & DOG \\
storm & FORM & SWARM & HAIL & SUM \\
snow & STOW & DOUGH & COLD & SUNK \\
clean & LEAN & SHEEN & BATH & MOUSE \\
trade & BLADE & LAID & SWAP & DARE \\
case & BASE & ACE & SUIT & CAP \\
run & FUN & WON & JUMP & AGREE \\
pool & TOOL & GHOUL & CUE & SKULL \\
goat & BOAT & NOTE & SHEEP & GAIN \\
tree & FREE & SHE & LEAF & TACK \\
bird & THIRD & HERD & CROW & TRUTH \\
hot & COT & AUGHT & HEAT & THROW \\
sky & SLY & LIE & CLOUD & STRAW \\
rock & SOCK & HAWK & HARD & WOLF \\
white & WRITE & FLIGHT & NURSE & TOWN \\
& & & &
\end{tabular}


APPENDIX A (continued)

\begin{tabular}{|c|c|c|c|c|}
\hline Target & $\begin{array}{l}\text { Phonemically Similar- } \\
\text { Graphemically Similar }\end{array}$ & $\begin{array}{l}\text { Phonemically Similar- } \\
\text { Graphemically Dissimilar }\end{array}$ & $\begin{array}{c}\text { Semantically } \\
\text { Related }\end{array}$ & Unrelated Control \\
\hline foot & SOOT & PUT & BARE & ODD \\
\hline pear & BEAR & CARE & FRUIT & WEED \\
\hline date & FATE & GREAT & BLIND & TIME \\
\hline sea & PEA & BEE & SALT & SENSE \\
\hline queen & SEEN & DEAN & KING & SPEECH \\
\hline hair & PAIR & WEAR & HEAD & TWINE \\
\hline hay & BAY & SLEIGH & BALE & WAIT \\
\hline state & SLATE & BAIT & CITY & EASE \\
\hline cry & DRY & SIGH & BABY & YOLK \\
\hline sun & BUN & TON & MOON & CRUST \\
\hline light & MIGHT & BITE & DARK & SQUASH \\
\hline raid & PAID & FADE & AIR & VIEW \\
\hline block & FROCK & WALK & SQUARE & VOTE \\
\hline pane & SANE & FEIGN & WINDOW & READ \\
\hline shake & FAKE & STEAK & MILK & POUCH \\
\hline dirt & SHIRT & HURT & GROUND & TRIP \\
\hline blue & GLUE & GREW & RED & VAULT \\
\hline dream & CREAM & SEEM & WISH & MEAN \\
\hline dance & LANCE & PANTS & SONG & HATCH \\
\hline mow & FLOW & THOUGH & LAWN & WAGE \\
\hline fight & SIGHT & KITE & WAR & THIRST \\
\hline pipe & RIPE & HYPE & STOVE & PRIZE \\
\hline girl & WHIRL & FURL & BOY & LIFE \\
\hline peace & LEASE & GEESE & DOVE & TERM \\
\hline sweet & SHEET & WHEAT & SOUR & STORE \\
\hline slow & BLOW & HOE & FAST & LOST \\
\hline ball & WALL & CRAWL & MOTH & PAIL \\
\hline here & MERE & NEAR & COME & STASH \\
\hline low & TOW & DOE & HIGH & NULL \\
\hline eat & BEAT & GREET & DRINK & TEND \\
\hline road & TOAD & MODE & CAR & DRAB \\
\hline fire & TIRE & LIAR & SMOKE & RISE \\
\hline go & NO & FOE & LEAVE & FLOOD \\
\hline nail & RAIL & PALE & TOE & THICK \\
\hline cone & LONE & LOAN & PINE & CASTE \\
\hline sleep & STEEP & HEAP & BED & LEARN \\
\hline wood & STOOD & COULD & SAW & DOWN \\
\hline horn & SCORN & WARN & FOG & KNOCK \\
\hline quart & WART & PORT & PINT & PRUNE \\
\hline noise & POISE & BOYS & LOUD & ROOF \\
\hline tall & FALL & HAUL & SHORT & TAIL \\
\hline food & MOOD & LEWD & $\mathrm{COOK}$ & RAFT \\
\hline speak & FREAK & CHIC & TALK & MISS \\
\hline home & DOME & ROAM & HOUSE & PHASE \\
\hline hole & POLE & BOWL & DEEP & LATE \\
\hline boot & ROOT & FLUTE & COWBOY & TART \\
\hline rough & TOUGH & CUFF & SMOOTH & GRAM \\
\hline roar & BOAR & FOUR & LION & SOAK \\
\hline shade & SPADE & MAID & LAMP & USE \\
\hline coat & OAT & QUOTE & RAIN & TRUCK \\
\hline night & RIGHT & SITE & DAY & HITCH \\
\hline steal & SEAL & FEEL & THIEF & PELT \\
\hline fear & DEAR & BEER & ANGER & REST \\
\hline wine & LINE & SIGN & BREAD & DENSE \\
\hline grief & BRIEF & REEF & JOY & PAGE \\
\hline
\end{tabular}


APPENDIX B

Words Used in Experiments 2 and 3

\begin{tabular}{|c|c|c|c|}
\hline Target & $\begin{array}{l}\text { Phonemically Similar- } \\
\text { Graphemically Similar }\end{array}$ & $\begin{array}{l}\text { Phonemically Similar- } \\
\text { Graphemically Dissimilar }\end{array}$ & Unrelated Control \\
\hline \multicolumn{4}{|c|}{ Common Set Targets } \\
\hline $\begin{array}{l}\text { FADE } \\
\text { HAIR } \\
\text { CEASE } \\
\text { CHUTE } \\
\text { COKE } \\
\text { SNOOP } \\
\text { TALE } \\
\text { GATE }\end{array}$ & $\begin{array}{l}\text { MADE } \\
\text { CHAIR } \\
\text { LEASE } \\
\text { MUTE } \\
\text { JOKE } \\
\text { TROOP } \\
\text { BALE } \\
\text { HATE }\end{array}$ & $\begin{array}{l}\text { MAID } \\
\text { SWEAR } \\
\text { PIECE } \\
\text { FRUIT } \\
\text { CROAK } \\
\text { SOUP } \\
\text { RAIL } \\
\text { WEIGHT }\end{array}$ & $\begin{array}{l}\text { GUILT } \\
\text { EASE } \\
\text { RINSE } \\
\text { TRUST } \\
\text { WITCH } \\
\text { STAGE } \\
\text { DOME } \\
\text { BLOOD }\end{array}$ \\
\hline $\begin{array}{l}\text { STEED } \\
\text { CURL } \\
\text { HOLE } \\
\text { LOOSE } \\
\text { GAME } \\
\text { RAKE } \\
\text { SEAM } \\
\text { BURN }\end{array}$ & $\begin{array}{l}\text { FEED } \\
\text { FURL } \\
\text { ROLE } \\
\text { GOOSE } \\
\text { SAME } \\
\text { LAKE } \\
\text { TEAM } \\
\text { TURN }\end{array}$ & $\begin{array}{l}\text { READ* } \\
\text { EARL } \\
\text { GOAL } \\
\text { SLUICE } \\
\text { CLAIM } \\
\text { STEAK } \\
\text { THEME } \\
\text { YEARN }\end{array}$ & $\begin{array}{l}\text { HATCH } \\
\text { PLANK } \\
\text { ONCE } \\
\text { SCALE } \\
\text { WRECK } \\
\text { DROOL } \\
\text { BARN } \\
\text { CAST }\end{array}$ \\
\hline $\begin{array}{l}\text { CONE } \\
\text { PUFF } \\
\text { PAIN } \\
\text { FALL } \\
\text { BEER } \\
\text { DIME } \\
\text { SCORE } \\
\text { DRUM }\end{array}$ & $\begin{array}{l}\text { BONE } \\
\text { STUFF } \\
\text { RAIN } \\
\text { CALL } \\
\text { DEER } \\
\text { CRIME } \\
\text { CORE } \\
\text { GLUM }\end{array}$ & $\begin{array}{l}\text { FLOWN } \\
\text { TOUGH } \\
\text { REIN } \\
\text { HAUL } \\
\text { PIER } \\
\text { THYME } \\
\text { POUR } \\
\text { COME }\end{array}$ & $\begin{array}{l}\text { DIRT } \\
\text { FORM } \\
\text { LIST } \\
\text { NEWS } \\
\text { PARK } \\
\text { ROAM } \\
\text { WAIT } \\
\text { AID }\end{array}$ \\
\hline $\begin{array}{l}\text { RARE } \\
\text { DAY } \\
\text { DRY } \\
\text { GROW } \\
\text { ROOM } \\
\text { NUN } \\
\text { BIKE } \dagger \\
\text { FIST } \dagger \\
\text { FREEZE } \ddagger \\
\text { CREW } \ddagger\end{array}$ & $\begin{array}{l}\text { BARE } \\
\text { HAY } \\
\text { FLY } \\
\text { FLOW } \\
\text { DOOM } \\
\text { SUN } \\
\text { HIKE } \\
\text { MIST } \\
\text { BREEZE } \\
\text { GREW }\end{array}$ & $\begin{array}{l}\text { THEIR } \\
\text { SLEIGH } \\
\text { NIGH } \\
\text { THOUGH } \\
\text { PLUME } \\
\text { ONE } \\
\text { DYKE } \\
\text { CYST } \\
\text { TEASE } \\
\text { CLUE }\end{array}$ & $\begin{array}{l}\text { FUSE } \\
\text { THICK } \\
\text { PUSH } \\
\text { REAR } \\
\text { PAGE } \\
\text { MEAN } \\
\text { FLEET } \\
\text { GULP } \\
\text { GUEST } \\
\text { BROOM }\end{array}$ \\
\hline \multicolumn{4}{|c|}{ Rare Set Targets } \\
\hline $\begin{array}{l}\text { LAID } \\
\text { WEAR } \\
\text { NIECE } \\
\text { SUIT } \\
\text { SOAK } \\
\text { GROUP } \\
\text { JAIL } \\
\text { EIGHT }\end{array}$ & $\begin{array}{l}\text { MAID } \\
\text { SWEAR } \\
\text { PIECE } \\
\text { FRUIT } \\
\text { CROAK } \\
\text { SOUP } \\
\text { RAIL } \\
\text { WEIGHT }\end{array}$ & $\begin{array}{l}\text { MADE } \\
\text { CHAIR } \\
\text { LEASE } \\
\text { MUTE } \\
\text { JOKE } \\
\text { TROOP } \\
\text { BALE } \\
\text { HATE }\end{array}$ & $\begin{array}{l}\text { AUTO } \\
\text { LOAD } \\
\text { MOTEL } \\
\text { PEAL } \\
\text { PLAIN } \\
\text { SAINT } \\
\text { SEIZE } \\
\text { SPITE }\end{array}$ \\
\hline $\begin{array}{l}\text { BEAD } \\
\text { PEARL } \\
\text { COAL } \\
\text { JUICE } \\
\text { AIM } \\
\text { BREAK } \\
\text { SCHEME } \\
\text { LEARN }\end{array}$ & $\begin{array}{l}\text { READ* } \\
\text { EARL } \\
\text { GOAL } \\
\text { SLUICE } \\
\text { CLAIM } \\
\text { STEAK } \\
\text { THEME } \\
\text { YEARN }\end{array}$ & $\begin{array}{l}\text { FEED } \\
\text { FURL } \\
\text { ROLE } \\
\text { GOOSE } \\
\text { SAME } \\
\text { LAKE } \\
\text { TEAM } \\
\text { TURN }\end{array}$ & $\begin{array}{l}\text { TOAST } \\
\text { SWING } \\
\text { TOWN } \\
\text { WALTZ } \\
\text { WORTH } \\
\text { SLANT } \\
\text { THREW } \\
\text { GRIEF }\end{array}$ \\
\hline $\begin{array}{l}\text { BLOWN } \\
\text { ROUGH } \\
\text { VEIN } \\
\text { MAUL }\end{array}$ & $\begin{array}{l}\text { FLOWN } \\
\text { TOUGH } \\
\text { REIN } \\
\text { HAUL }\end{array}$ & $\begin{array}{l}\text { BONE } \\
\text { STUFF } \\
\text { RAIN } \\
\text { CALL }\end{array}$ & $\begin{array}{l}\text { FLEET } \\
\text { MONTH } \\
\text { MEAL } \\
\text { REST }\end{array}$ \\
\hline
\end{tabular}


APPENDIX B (continued)

\begin{tabular}{|c|c|c|c|}
\hline Target & $\begin{array}{l}\text { Phonemically Similar- } \\
\text { Graphemically Similar }\end{array}$ & $\begin{array}{l}\text { Phonemically Similar- } \\
\text { Graphemically Dissimilar }\end{array}$ & Unrelated Control \\
\hline TIER & PIER & DEER & CHEAT \\
\hline RHYME & THYME & CRIME & HENCE \\
\hline FOUR & POUR & CORE & TRASH \\
\hline SOME & COME & GLUM & STALL \\
\hline HEIR & THEIR & BARE & BRICK \\
\hline NEIGH & SLEIGH & HAY & VALVE \\
\hline SIGH & NIGH & FLY & TWIN \\
\hline DOUGH & THOUGH & FLOW & MIGHT \\
\hline FLUME & PLUME & DOOM & NURSE \\
\hline DONE & ONE & SUN & FLUTE \\
\hline TYKE $\dagger$ & DYKE & HIKE & PLUG \\
\hline TRYST + & CYST & MIST & TWINE \\
\hline PLEASE $\ddagger$ & TEASE & BREEZE & FLOUR \\
\hline GLUE $\ddagger$ & CLUE & GREW & RISK \\
\hline
\end{tabular}

*The phonemically ambiguous word READ was replaced with the phonemically unambiguous word PLEAD for Experiment 3. †Used in Experiment 2 only. †Used in Experiment 3 only.

APPENDIX C

Responses to Filler Items, Experiments 2-5

\begin{tabular}{|c|c|c|c|c|}
\hline Type of Filler Trial & RTs & $(S D)$ & Errors & $(S D)$ \\
\hline \multicolumn{5}{|l|}{ Experiment 2} \\
\hline Word prime-graphemically similar-phonemically dissimilar word target & 571 & (159) & $3.6 \%$ & (1.1) \\
\hline Word prime-graphemically similar nonword target & 660 & (119) & $13.9 \%$ & (3.1) \\
\hline Word prime-graphemically dissimilar nonword target & 669 & (120) & $6.7 \%$ & (2.0) \\
\hline Nonword prime-word target & 603 & (140) & $3.9 \%$ & (1.1) \\
\hline Nonword prime-nonword target & 650 & (137) & $1.7 \%$ & (0.6) \\
\hline Neutral control prime-nonword target & 676 & (137) & $5.3 \%$ & (1.3) \\
\hline \multicolumn{5}{|l|}{ Experiment 3} \\
\hline Word prime-graphemically similar-phonemically dissimilar word target & 623 & $(168)$ & $5.6 \%$ & (1.7) \\
\hline Word prime-graphemically similar nonword target & 679 & (141) & $8.3 \%$ & (2.5) \\
\hline Word prime-graphemically dissimilar nonword target & 697 & (170) & $5.2 \%$ & (1.8) \\
\hline Nonword prime-word target & 588 & (129) & $3.3 \%$ & (1.6) \\
\hline Nonword prime-nonword target & 685 & (158) & $4.0 \%$ & (1.6) \\
\hline Neutral control prime-nonword target & 684 & (126) & $3.7 \%$ & (1.2) \\
\hline \multicolumn{5}{|l|}{ Experiment 4} \\
\hline \multicolumn{5}{|l|}{$250-\mathrm{msec}$ SOA } \\
\hline Word prime-graphemically similar-phonemically dissimilar word target & 641 & (149) & $8.67 \%$ & (2.1) \\
\hline Word prime-graphemically similar nonword target & 685 & (143) & $9.33 \%$ & (2.0) \\
\hline Word prime-graphemically dissimilar nonword target & 756 & (184) & $10.0 \%$ & (2.5) \\
\hline Nonword prime-nonword target & 712 & (126) & $6.67 \%$ & (1.7) \\
\hline Neutral control prime-nonword target & 713 & (126) & $8.67 \%$ & (2.1) \\
\hline \multicolumn{5}{|l|}{1,000 -msec SOA } \\
\hline Word prime-graphemically similar-phonemically dissimilar word target & 609 & (118) & $7.33 \%$ & (1.9) \\
\hline Word prime-graphemically similar nonword target & 701 & (116) & $7.33 \%$ & (1.7) \\
\hline Word prime-graphemically dissimilar nonword target & 725 & (133) & $12.67 \%$ & (2.0) \\
\hline Nonword prime-nonword target & 737 & (153) & $7.33 \%$ & $(1.4)$ \\
\hline Neutral control prime-nonword target & 727 & $(162)$ & $12.67 \%$ & (1.6) \\
\hline \multicolumn{5}{|l|}{ Experiment 5} \\
\hline Word prime-graphemically similar-phonemically dissimilar word target & 551 & (146) & $6.0 \%$ & (1.5) \\
\hline Word prime-graphemically similar nonword target & 639 & (105) & $12.0 \%$ & (2.2) \\
\hline Word prime-graphemically dissimilar nonword target & 685 & (119) & $6.0 \%$ & (1.4) \\
\hline Nonword prime-nonword target & 633 & (108) & $9.0 \%$ & (1.8) \\
\hline Neutral control prime-nonword target & 710 & $(146)$ & $8.0 \%$ & $(1.7)$ \\
\hline
\end{tabular}

Note-estimates in parentheses are standard deviations computed by subject for each condition. 